\title{
Comparison of HIPIMS sputtered Ag- and Cu-surfaces leading to accelerated bacterial inactivation in the dark
}

\author{
Sami Rtimi ${ }^{\mathrm{a}}$, Oualid Baghriche ${ }^{\mathrm{a}}$, Cesar Pulgarin ${ }^{\mathrm{a}, * *}$, Arutiun Ehiasarian ${ }^{\mathrm{b}}$, Ralf Bandorf ${ }^{\mathrm{c}}$, John Kiwi ${ }^{\mathrm{d}, *}$ \\ a Ecole Polytechnique Fédérale de Lausanne, EPFL-SB-ISIC-GPAO, Station 6, CH-1015, Lausanne, Switzerland \\ b Sheffield Hallam Univ, Howard St, Sheffield, S1 1WB, UK \\ c Fraunhofer-Institute for Surface Engineering and Thin Films (IST), Bienroder Weg 54E, 38108 Braunschweig, Germany \\ d Ecole Polytechnique Fédérale de Lausanne, EPFL-SB-ISIC-LPI, Bat Chimie, Station 6, CH1015, Lausanne, Switzerland
}

\section{A R T I C L E I N F O}

Available online 20 February 2014

Keywords:

HIPIMS sputtering

Bacterial inactivation

Dark

\begin{abstract}
A B S T R A C T
Recently, compact uniform and adhesive films of $\mathrm{Ag}$ and $\mathrm{Cu}$ have been prepared by DC-magnetron sputtering (DC), pulsed DC magnetron sputtering (DCP) and high power impulse magnetron sputtering (HIPIMS). This study reports the HIPIMS deposition for $\mathrm{Ag}$ and $\mathrm{Cu}$ on textile fabrics, the bacterial inactivation kinetics and the nature of the species in the plasma produced during HIPIMS sputtering. The deposition rates of $\mathrm{Ag}$ and $\mathrm{Cu}$ atoms and the bacterial inactivation times are reported in the dark and under light as a function of the applied peak currents during the sputtering by HIPIMS. By X-ray photoelectron spectroscopy (XPS), the surface percentage atomic concentration and the oxidation state changes are reported during bacterial inactivation. The Ar and metal-ions produced in the magnetron chamber were determined by mass spectroscopy (QMS). A mechanism for the bacterial inactivation is suggested for $\mathrm{Ag}$ and Cu HIPIMS sputtered surfaces.
\end{abstract}

(c) 2014 Elsevier B.V. All rights reserved.

\section{Introduction}

The ambient contamination by biofilms spreading bacteria for long times in hospitals, schools and many public places requires the preparation of adhesive antibacterial/fungi thin films showing rapid biocidal kinetics. Antimicrobial nanoparticulate film preparation is a topic of increasing attention since they can reduce/eliminate the formation of infectious bacteria biofilms leading to hospital acquired infections (HAI) [1]. The microbes causing HAI have two properties: many of them are toxic/resistant to antibiotics and they survive on hospital surfaces for long times [2]. These nosocomial infections due to antibiotic resistant bacteria are becoming more frequent during the last decade and contribute to the increasing of hospital care costs. The level of contamination of public hospitals in the UK and Switzerland has been found to be higher than the allowed level set for hospital rooms. For example, the contamination of $10^{5} \mathrm{CFU} / \mathrm{cm}^{2}$ was observed in a diabetic wound dressing. But in the vicinity of the patient, a microbial density of $10^{2} \mathrm{CFU} / \mathrm{cm}^{2}$ was found. Disinfecting surfaces were applied and strongly decrease the microbial density, since bacterial concentration was not high and re-growth of bacteria was not observed [3]. This observation warrants the investigation of antibacterial surfaces as addressed in the present study.

\footnotetext{
* Corresponding author. Tel.: +4121693 6150; fax: +41216935690.

** Corresponding author. Tel: +4121 693 4720; fax: +4121 6935690.

E-mail addresses: cesar.pulgarin@epfl.ch (C. Pulgarin), john.kiwi@epfl.ch (J. Kiwi).
}

Colloidal deposition of surfaces, like textiles and other materials is applied widely to prepare disinfectant/antibacterial materials. In our laboratory Ag-colloids were reduced by isopropanol and precipitated by ammonia on the textile surface inducing bactericide behaviour [4]. In a further study, Ag-colloids were fixed on cotton to investigate their antibacterial kinetics in the dark [5]. Antibacterial Cu-colloid loading textile surfaces have been reported leading to efficient antibacterial activity [6,7]. The colloid or sol-gel preparation deposited films are not mechanically stable, nor reproducible, and present low uniformity and little adhesion since they can be wiped off by a cloth or thumb [8]. This moved us to work on the sputtering of antibacterial films to overcome the shortcomings of colloidal loaded films. The HIPIMS sputtered films presenting a progress compared to films sputtered by more traditional approaches like DC and DCP. CVD/PDV deposition methods present some disadvantages and this will be discussed in the next paragraph. The problem to fix colloids on surfaces encountered during CVD deposition is in connection with the heat needed for the film fixation on the substrate. This has to be resistant to heat. Deposition by sputtering of metal/oxides/semiconductors on non-heat resistant substrates is possible since the polymer thin films, textiles and plastics can be heated at temperatures up to $150{ }^{\circ} \mathrm{C}$.

In a typical CVD process, the substrate is exposed to the volatile precursors. Due to the applied heat the precursor decomposes on the substrate surface depositing amorphous/polycrystalline coatings. The volatile species condense on the substrate having a lower temperature. The disadvantages of conventional PVD deposition approach are: the high investment costs and the high temperatures needed precluding 
film deposition on textiles besides the large amount of heat used requiring costly cooling systems. Recently, Foster et al. [9], Yates et al. [10], Musil et al. [11], and Brooks et al. [12] have reported antibacterial Ag and $\mathrm{Cu}$ coatings on glass and polymer films depositing the metal/oxides by CVD.

Ag-nanoparticles exhibit bacterial and fungicidal properties. They can accumulate on the cell wall of bacteria and release Ag-ions that due to their small size penetrate into the cells through the wall porins [13]. Ag-nanoparticles affect the bacteria respiratory enzyme due to the production of ROS and associated DNA damage leading to death [14]. The release of Ag-ions from Ag-grafted surfaces involves Agoxidation reactions due to the oxygen available to the Ag-clusters, protons, and salts and is directly dependent on the Ag-particle size that for large particles is effective only when releasing Ag-ions in sufficient concentrations and in a sustained way over long time periods [15].

The field of antibacterial $\mathrm{Cu}$-film preparation and evaluation has gained much attention during the last decade since they have been reported to be effective in reducing hospital-acquired infections (HAI) [16]. Since the effect of Cu-ions is extremely toxic to bacteria at very low concentrations (ppb range) many formulations of surfaces and implants coated with $\mathrm{Cu}$ present a higher cytocompatibility than $\mathrm{Ag}$ for mammalian cells. $\mathrm{Cu}$ is a metabolizable agent [17] compared to $\mathrm{Ag}$ that stays in the body after ingestion increasing the Ag-serum levels [18]. The antibacterial effects of $\mathrm{Cu}-\mathrm{TiO}_{2}$ coatings against MRSA have been reported by $\mathrm{Cu}-\mathrm{TiO}_{2}$ coating thickness, the layers on medical devices showing high mechanical stability without cracks in the coating [19]. The area of sputtering on medical devices is a current area of research. Hashimoto et al. [20] have reported the preparation of the $\mathrm{Cu}$ and $\mathrm{TiO}_{2} / \mathrm{Cu}$ films by sol-gel methods presenting bactericide action under visible light. Further colloidal $\mathrm{Cu}$-coated textiles showing antibacterial properties have been prepared and tested in our laboratory [21,22]. The particular interest in Cu-textiles is based on the fact that the porous hydrophilic structure of textiles provides a suitable environment for bacterial growth. Cu-nanoparticles have shown recently to produce strong antibacterial effects in textiles designed for medical applications $[6,7]$.

The improvement in the performance and utility of $\mathrm{Ag}$ and $\mathrm{Cu}$ antibacterial films is to produce a film microstructure inducing an accelerated bacterial inactivation concomitant with toxicity below the accepted standards set for its use in medical applications [23]. The film uniformity, stable structure and adhesive properties are currently under investigation by academic institutions and pharma/biotechnology companies producing devices for medical device implants covered with antibacterial coatings [24]. The regular, periodic and continuous elution of antibiotics and antiseptics (or both) added on medical devices and implants over long period of times is the central problem to avoid infections that lead to the replacement of the implants after some time. HIPIMS sputtered devices/surfaces with $\mathrm{Ag}$, $\mathrm{Cu}$ or both eluting Ag-ions and $\mathrm{Cu}$-ions over long times could be a solution to this problem and need a long term testing by ion coupled mass spectrometry (ICP-MS), X-ray fluorescence (XRF) and XPS. The long-term testing for the elusive properties of the Ag, Cu HIPIMS surface is under way in our laboratory and will be reported elsewhere at a later date.

HIPIMS generates high-density plasma ionizing the metal to a high degree at low pressures avoiding the formation of macro-particles that deteriorate the properties of the growing film. The development of HIPIMS in the last decade is due to the growing demand for high quality anticorrosive films in aircraft, car industry and other industrial sectors. Recently, high power pulsed magnetron sputtering (HIPIMS) has gained increasing attention as a more advanced sputtering method to deposit uniform, robust films onto a variety of substrates. This is due to the high pulse power densities of several kW leading to elimination of growth defects and concomitant densification of the sputtered films [25]. The enhanced densification attained by sputtering with HIPIMS is due to the high ion-to neutral-ratio found in the plasma during the deposition process compared to more traditional forms of sputtering. In conventional DC-sputtering, the degree of ionization is $1 \%-5 \%$ and the electronic density $\sim 10^{14} \mathrm{e}^{-} / \mathrm{m}^{3}$. The majority of the particles reaching the substrate are made up of Ar-ions [26]. In DCP-sputtering, the electronic density $\sim 10^{16} \mathrm{e}^{-} / \mathrm{m}^{3}$ and the ionization are higher compared to DC. In the case of HIPIMS, pulses from one microsecond up to milliseconds generate current densities of $\sim 10^{18} \mathrm{e}^{-} / \mathrm{m}^{3}$ which is $10^{4}$ times higher than that obtained with conventional DC-sputtering and the degree of ionization reaches about 50-80\% [27-30]. Improvement in the film homogeneity is achieved by HIPIMS as a consequence of the high ion-fraction of the sputtered metal(s). Until now, the use of DC, pulse sputtering (DCP) and HIPIMS sputtering to deposit bactericide metal nanoparticles films precluding bacterial inactivation has not been widely investigated for the large scale production of hospital personnel (clothing), bedding textiles, towels, curtains, chairs, floors, and medical implants.

\section{Experimental section}

2.1. HIPIMS-sputtering on polyester, materials, film thickness calibration and XRF evaluation of $\mathrm{Ag}$ and $\mathrm{Cu}$

The HIPIMS deposition of metals was carried out in a CMS-18 vacuum system from Kurt Lesker Ltd. evacuated to $10^{-5}$ Pa by a turbomolecular pump [31]. Fig. 1 shows the scheme of the HIPIMS chamber. The Cu-target was $5 \mathrm{~cm}$ in diameter, 99.99\% pure from $\mathrm{K}$. Lesker Ltd. UK. The mass spectrometry measurements were carried out in a Hiden Analytical Ltd PSM003 unit to determine the ioncomposition of the ions in the plasma Ar-atmosphere [32]. The HIPIMS was operated at $100 \mathrm{~Hz}$ with pulses of $100 \mathrm{~ms}$ separated by $10 \mathrm{~ms}$. The HIPIMS short pulses avoid a glow-to-arc transition during plasma particle deposition.

The polyester used corresponds to the EMPA test cloth sample No 407. It is a polyester Dacron, type 54 spun, plain weave ISO 105-F04 used for color fastness determinations. The metal content on the substrates was evaluated by X-ray fluorescence (XRF). The spectrometer used was RFX, PANalytical PW2400.

\subsection{Escherichia coli and MRSA counting method during bacterial inactivation}

The samples of Escherichia coli (E. coli K12) was obtained from the Deutsche Sammlung von Mikroorganismen und Zellkulturen GmbH (DSMZ) ATCC23716, Braunschweig, Germany, to test the antibacterial activity of the $\mathrm{Ag}$ and $\mathrm{Cu}$ sputtered samples. The $100 \mu \mathrm{L}$ culture aliquots with an initial concentration of $\sim 10^{6} \mathrm{CFU} \mathrm{mL}{ }^{-1}$ in $\mathrm{NaCl} / \mathrm{KCl}$ ( $\mathrm{pH} 7$ ) were placed on coated and uncoated (control) polyethylene fabric. A well-

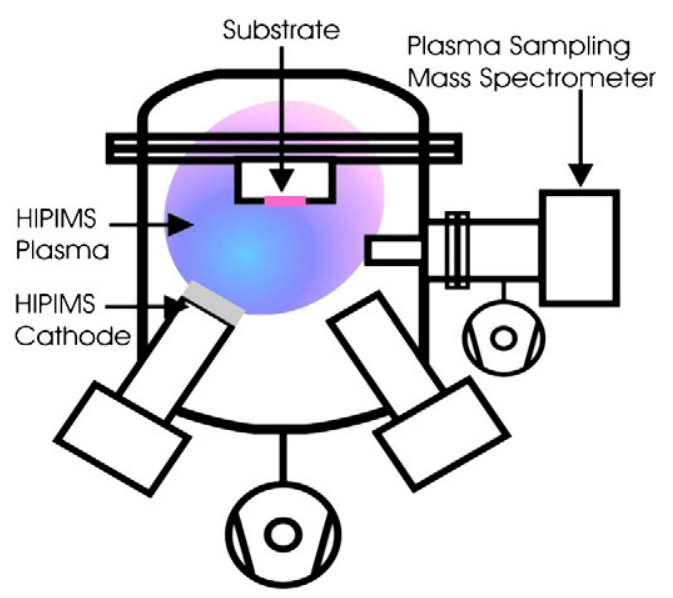

Fig. 1. Schematic of the HIPIMS sputtering unit used for the sputtering of substrates. 
dispersed non-heterogeneous contact is established between the sample and the bacterial solution. $100 \mu \mathrm{L}$ of the $E$. coli solution was contacted with the $\mathrm{TiO}_{2}$ uniform films. The distribution of bacteria on the substrate turned out to be homogeneous and was in a position to contact the inoculated cells on contact. The exposition was done at ambient temperature. The samples were then placed on Petri dishes provided with a lid to prevent evaporation. After each determination, the fabric was transferred into a sterile $2 \mathrm{~mL}$ Eppendorf tube $(900 \mu \mathrm{L})$ autoclaved $\mathrm{NaCl} / \mathrm{KCl}$ saline solution. This solution was subsequently mixed thoroughly using a vortex for $3 \mathrm{~min}$. Serial dilutions were made in $\mathrm{NaCl} / \mathrm{KCl}$ solution. A sample of $100 \mu \mathrm{L}$ of each CFU run was pipetted onto a nutrient agar plate and then spread over the surface of the plate using the standard plate method. Agar plates were incubated lid down, at $37{ }^{\circ} \mathrm{C}$ for $24 \mathrm{~h}$ before colonies were counted. Three independent assays were done for each sputtered sample. The CFU statistical analysis was performed calculating the standard deviation values. The average values were compared by one-way analysis of variance and with the value of statistical significance. The one-way analysis of variance (one-way ANOVA) was used to compare the mean of the samples using the Fisher distribution. The response variable was approximated for the sample data obtained from the photocatalytic inactivation of test samples presenting the same distribution within the same sputtering time.

The Staphylococcus aureus strain used for this study was the MRSA ATCC 43300 strain. Bacteria were stored at $-80{ }^{\circ} \mathrm{C}$. Overnight cultures for bacterial inoculate were prepared in brain heart infusion (BHI) media (OXOID, Basingstoke, UK) from a single colony picked on a $\mathrm{BHI}$ agar plate and incubated at $37^{\circ} \mathrm{C}$ for $16 \mathrm{~h}$. The inoculation of polyester fabrics was performed in the following way: squares of polyester and $\mathrm{Cu}$-sputtered polyester were inoculated with $10^{7} \mathrm{CFU}$. After the inoculation, samples were placed in a humidified chamber and the viability of the bacteria was assessed at several times. The inoculated coupons were placed in a $2 \mathrm{~mL}$ Eppendorf containing $1 \mathrm{~mL} \mathrm{NaCl} 0.9 \%$ and bacteria were detached by vortexing ( $3 \mathrm{~min}$ ). Bacterial counts were performed by plating the re-suspended bacteria on BHI agar-plates [33].

\subsection{ICP-MS during bacterial inactivation and mass spectroscopy (QMS) of samples}

Inductively coupled plasma spectrometry (ICP-MS) was used to determine the $\mathrm{Cu}$ since it is a sensitive analytical technique due to the low background and high ion transmission. The Finnigan ${ }^{\mathrm{TM}}$ ICPS used was equipped with a double focusing reverse geometry mass spectrometer with a resolution of $1.2 \times 10^{5} \mathrm{cps} / \mathrm{ppb}$ and a detection limit of $0.2 \mathrm{ng} / \mathrm{L}$. Samples $1 \mathrm{~cm}^{2}$ were placed in Eppendorf tubes containing $1 \mathrm{~mL}(\mathrm{NaCl} / \mathrm{KCl} 0.08 \%$ solution). The solutions were then diluted 10 times to reach the volume necessary for the ICP-MS analyses.

The mass spectrometry measurements were carried out in a Hiden Analytical Ltd PSM003 unit attached to the sputtering unit to determine the ion-composition of the ions in the Ar-plasma at different currents [32].

\subsection{X-ray photoelectron spectroscopy of Ag, Cu-films (XPS)}

An AXIS NOVA photoelectron spectrometer (Kratos Analytical, Manchester, UK) equipped with monochromatic $\mathrm{AlK}_{\alpha}(h \nu=1486.6 \mathrm{eV})$ anode was used. The electrostatic charge effects on the samples were compensated by means of the low-energy electron source working in combination with a magnetic immersion lens. The carbon $\mathrm{C} 1 \mathrm{~s}$ line with position at $284.6 \mathrm{eV}$ was used as a reference to correct the charging effect. The quantitative surface atomic concentration of some elements was determined from peak areas using sensitivity factors [34,35]. Spectrum background was subtracted/corrected for electrostatic charging according to Shirley [36]. The XPS spectra for the Cu-species were analyzed by means of spectra deconvolution software (CasaXPS-Vision 2, Kratos Analytical UK).

\section{Results and discussion}

\subsection{Film thickness calibration and determination of metal-content}

Fig. 2 presents the nominal calibration of the Ag-thin coating attained by HIPIMS for currents 1,2 and $5 \mathrm{~A}$. Taking the lattice distance between Ag-atoms as $0.3 \mathrm{~nm}$ [37] a monolayer of $\mathrm{Ag}$ is estimated to have a density of $10^{15}$ atoms $/ \mathrm{cm}^{2}$. HIPIMS sputtering at 2 A deposited a coating $\sim 100 \mathrm{~nm}$ thick after $160 \mathrm{~s}$. It follows that in one second, a layer of $0.62 \mathrm{~nm}$ was deposited and if each atomic layer is taken as $0.2 \mathrm{~nm}$ thick, then a rate of deposition of $\sim 3$ layers per second was deposited equivalent to a silver deposition rate of $3 \times 10^{15}$ atoms $/ \mathrm{cm}^{2} \mathrm{~s}$. Table 1 presents the Ag wt.\%/wt. polyester and the thickness of the Ag-layers deposited by HIPIMS at different times.

The calibration of the $\mathrm{Cu}$-nanoparticulate film thickness by HIPIMS on the Si-wafers is shown in Fig. 3. The thicknesses of the $\mathrm{Cu}$-loading of the Cu-films sputtered by HIPIMS are shown in Table 2. The calibration reported in Fig. 3 presented a 10-15\% experimental error. The $20 \mathrm{~s}$ HIPIMS deposition time with 6 A led to a film thickness of $28 \mathrm{~nm}$. With 60 Amps a $28 \mathrm{~nm}$ layer was deposited (see Fig. 3) within $60 \mathrm{~s}$ equivalent to 140 layers with a content of $1.4 \times 10^{17}$ atoms $\mathrm{Cu} / \mathrm{cm}^{2}$. This is a deposition ratio for $\mathrm{Cu}$ of $2.3 \times 10^{15} \mathrm{atoms} / \mathrm{cm}^{2} \mathrm{~s}$.

\subsection{E. coli inactivation kinetics and mechanism on Ag-polyester}

Fig. 4 presents the bacterial inactivation kinetics for Ag-polyester fabrics sputtered by HIPIMS at 5 A. This is the most suitable sample leading to a bacterial inactivation within $2 \mathrm{~h}$ requiring a sputtering time of 75 or $150 \mathrm{~s}$.

Fig. 5 shows the bacteria inactivation times as a function of the nominal thickness of the Ag-layers deposited by HIPIMS at $5 \mathrm{~A}$ and the layers deposited by direct current magnetron sputtering (DCMS) at $0.3 \mathrm{~A}$. Fig. 5 shows the significant savings of $\mathrm{Ag}$ and sputtering times by HIPIMS compared with the more traditional DCMS. Generally, one would expect more compact, denser metal films for HIPIMS to present reduced antibacterial efficacy. The results in Fig. 5 show the opposite effect. This can be explained by local softening of the polymer and possible void formation during the first stage of film growth on polymers due to the local higher temperatures available in the magnetron chamber during HIPIMS sputtering.

$\mathrm{Ag}$ samples in the dark by contact with ambient air containing water-vapor $\left(\mathrm{H}_{2} \mathrm{O}\right)_{\mathrm{v}}$ deposit AgOH on its surface. The favorable decomposition of $\mathrm{AgOH}$ leads to $\mathrm{Ag}_{2} \mathrm{O}$ as in (Eq. 1)

$\mathrm{AgOH} \rightarrow \mathrm{Ag}_{2} \mathrm{O}+\mathrm{H}_{2} \mathrm{O}(\mathrm{pk}=2.87)$

$\mathrm{Ag}_{2} \mathrm{O}$ is thermodynamically stable at $\mathrm{pH}$ 6-7 and leads to the bacterial inactivation of $E$. coli shown in Fig. 4. The hydrolysis and equilibrium

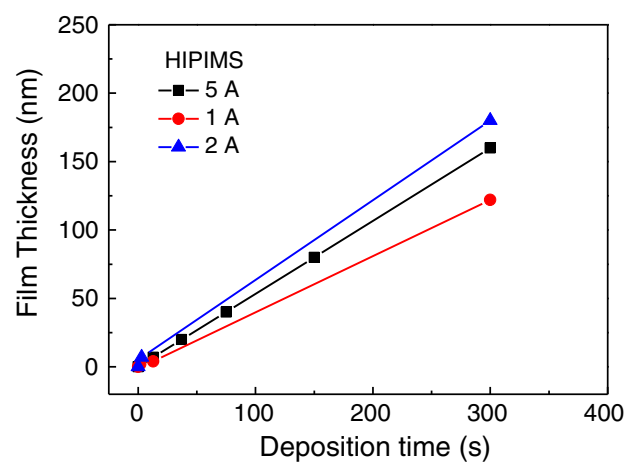

Fig. 2. Nominal calibration of the Ag thickness attained by HIPIMS for currents 1, 2 and $5 \mathrm{~A}$. 
Table 1

HIPIMS sputtering of Ag, relationship of HIPIMS sputtering time, the \% Ag wt./wt. polyester and $\mathrm{Ag}$ film thicknesses at 1,2 and 5 A.

\begin{tabular}{|c|c|c|c|}
\hline HIPIMS & Time $(\mathrm{s})$ & \% Ag wt./wt. & Ag film thickness $\mathrm{nm}$ \\
\hline $1 \mathrm{~A}$ & 2 & 0.002 & 2 \\
\hline $1 \mathrm{~A}$ & 13 & 0.003 & 4 \\
\hline $2 \mathrm{~A}(2)$ & 3 & 0.014 & 7 \\
\hline HIPIMS $5 \mathrm{~A}$ & Time $(\mathrm{s})$ & \% Ag wt./wt. & Thickness nm \\
\hline (2) & 13 & 0.0029 & 7 \\
\hline (3) & 37 & 0.0086 & 20 \\
\hline (4) & 75 & 0.0315 & 40 \\
\hline (5) & 150 & 0.0630 & 80 \\
\hline
\end{tabular}

of $\mathrm{Ag}_{2} \mathrm{O}$ have been reported [39]. Visible/actinic light irradiation photoactivates $\mathrm{Ag}_{2} \mathrm{O}$ with $1.46<\mathrm{bg}<2.25 \mathrm{eV}$ as noted next in Eq. (2)

$\mathrm{Ag}_{2} \mathrm{O}+$ light $\rightarrow \mathrm{Ag}_{2} \mathrm{O}\left(\mathrm{h}^{+}\right)+\mathrm{Ag}_{2} \mathrm{O}\left(\mathrm{e}^{-}\right)$

The $\mathrm{Ag}_{2} \mathrm{O}$ in Eqs. ((1)-(2)) reacts with $\mathrm{e}^{-}$induced by light irradiation Eq. (3)

$\mathrm{Ag}_{2} \mathrm{O}+\mathrm{e}^{-} \rightarrow \mathrm{Ag}^{\mathrm{o}}+\mathrm{O}_{2}$

The $\mathrm{O}_{2}$ shown in Eq. (3) promotes reactions $(5,6)$ producing highly oxidative radicals, while the $\mathrm{h}^{+}$in Eq. (2) reacts with $\mathrm{H}_{2} \mathrm{O}$ in Eq. (4). This reaction runs parallel with Eq. (5) generating $\mathrm{OH}^{\circ}$ radicals (or other highly reactive oxidative radicals) able to inactivate $E$. coli. The $\mathrm{h}^{+}$in Eq. (2) reacts with water-vapor leading to radical species

$\mathrm{h}^{+}+\mathrm{H}_{2} \mathrm{O} \rightarrow \mathrm{OH}^{\mathrm{o}}+\mathrm{H}^{+}$

and the $\mathrm{e}^{-}$in Eq. (2) reacts with water-vapor in the air $\left(\mathrm{O}_{2}\right)$ leading also to radical species

$\mathrm{e}^{-}+\mathrm{H}_{2} \mathrm{O}+\mathrm{O}_{2} \rightarrow \mathrm{OH}^{0}+\mathrm{OH}^{-}$

The silver nanoparticulate films exhibit the Volmer-Weber growth mechanism that assumes an island-by-island growth because of the large cohesive forces existing among the Ag-atoms. The strong coalescence of $\mathrm{Ag}$ after deposition allows the Ag-islands to grow into a nanoparticulate film as already reported for DCMS sputtered films [26,38] (Figs. 3 and 6). The interest in HIPIMS deposition of Ag is that the thin film $n<100 \mathrm{~nm}$ contains $\mathrm{Ag} / \mathrm{Ag}_{2} \mathrm{O} / \mathrm{AgO}$ effective in inactivating pathogens $[3,23,24]$.

\subsection{E. coli inactivation kinetics and mechanism on Cu-polyester and redox catalysis}

Fig. 6a presents the inactivation kinetics of $E$. coli on Cu-polyester HIPIMS sputtered for $3 \mathrm{~s}$ and $60 \mathrm{~s}$ at 60 Amps. It is readily seen that at longer HIPIMS sputtering times, the inactivation time for $E$. coli becomes

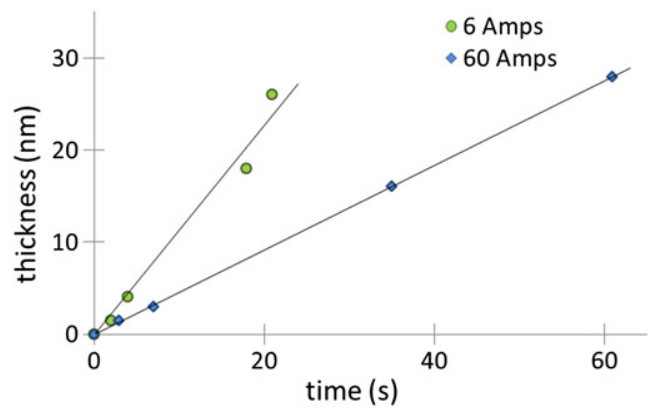

Fig. 3. Nominal calibration of the Cu thickness layers sputtered by HIPIMS at $6 \mathrm{~A}$ and $60 \mathrm{~A}$.
Table 2

Sputtering time, thickness and \% Cu wt./wt. of the Cu-layers sputtered by HIPIMS on polyester at 6 and 60 Amps.

\begin{tabular}{ccccc}
\hline & Deposition time [s] & {$[$ Amps] } & Thickness [nm] & Cu [\%-wt.] \\
\hline HIPIMS & 2 & 6 & 1.5 & 0.0121 \\
& 4 & 6 & 4 & 0.0200 \\
18 & 6 & 16 & 0.0600 \\
21 & 6 & 28 & 0.1120 \\
3 & 60 & 1.5 & 0.0073 \\
7 & 60 & .3 & 0.0182 \\
35 & 60 & 16 & 0.0675 \\
61 & 60 & 28 & 0.1020
\end{tabular}

shorter. A local softening of the fibers at the contact sites with Cu may play a significant role in the inactivation time of $E$. coli due to the effect of higher temperatures available to the substrate [25,26]. The Cu-atoms diffuse anisotropically on the textile surface and the diffusion is driven by the high energy given to the $\mathrm{Cu}$-ions. The high energy given to the $\mathrm{Cu}$-ions is partly released when the $\mathrm{Cu}$-ions arrive at the polyester surface and contact with surface electrons or bond with the textile surface [37].

Fig. $6 \mathrm{~b}$ shows the release of Cu-ions inactivating E. coli as a function of catalyst recycling up to the 8th cycle by ICP-MS. The release of $\mathrm{Cu}^{-}$from the $\mathrm{TiO}_{2} / \mathrm{Cu}$ samples shown in Fig. 6b was $\sim 8 \mathrm{ppb} / \mathrm{cm}^{2}$. This value is lower compared to the Cu-release from the Cu-HIPIMS sputtered samples of to $\sim 18 \mathrm{ppb} \mathrm{Cu} / \mathrm{cm}^{2}$ at the end of the 8th cycle. In both cases the amounts of $\mathrm{Cu}$ are not to be cytotoxic to mammalian cells $[17,19,38]$ and proceed through an oligodynamic effect [23] being in principle possible to be used to induce bacterial inactivation on implants in a way that it is not toxic to human health. The antibacterial effects of $\mathrm{Cu}$-nanoparticulate films shown in Fig. 6b as well as for the case of Ag-nanoparticles films leaching $\mathrm{Ag}$-species are due to $\mathrm{Cu}$-ions and $\mathrm{Ag}$-ions diffusing through the cell-wall porins into the cell core leading to cell death.

Fig. $6 \mathrm{c}$ in shows the methicillin resistant S. aureus (MRSA) inactivation in the dark by HIPIMS Cu-polyester sputtered with the same power (60 A) as applied in the samples used to inactivate bacteria (Fig. 6a). The times necessary to inactivate MRSA are similar to the times required to inactivate $E$. coli when starting with the same $\mathrm{CFU}$ bacterial concentration. This is not surprising since both involve the destruction of organic matter. This is an important observation with a wide application potential. Dark bacterial inactivation is important in hospital facilities. It also avoids the formation of pathogens biofilm formation leading to hospital acquired infections (HAI) as described in the first paragraph of the Introduction.

Table 3 shows the surface atomic composition \% for the main elements on the $\mathrm{Cu}$-polyester as a function of the bacterial inactivation time. The surface $\mathrm{C}$ in the films at time zero decreases with respect to pure polyester due to the sputtered $\mathrm{Cu}$. When contacted with bacteria (Table 2, third column) the C-content in the sample is seen to decrease again due to the $\mathrm{Cu}$-mediated bacterial degradation. At longer reaction

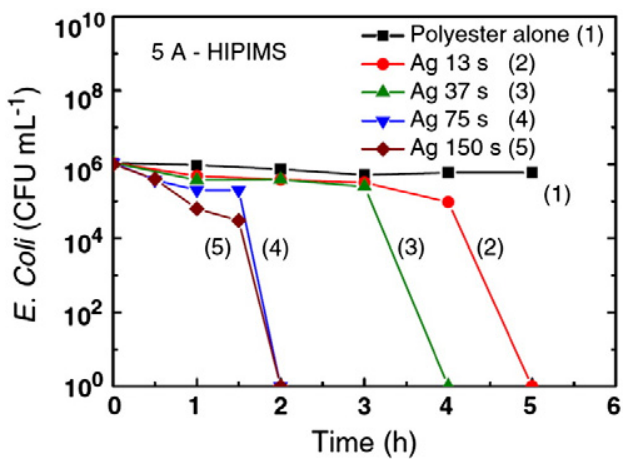

Fig. 4. E. coli inactivation as a function of time for Ag-polyester sputtered at $5 \mathrm{~A}$ for different times in the dark. 


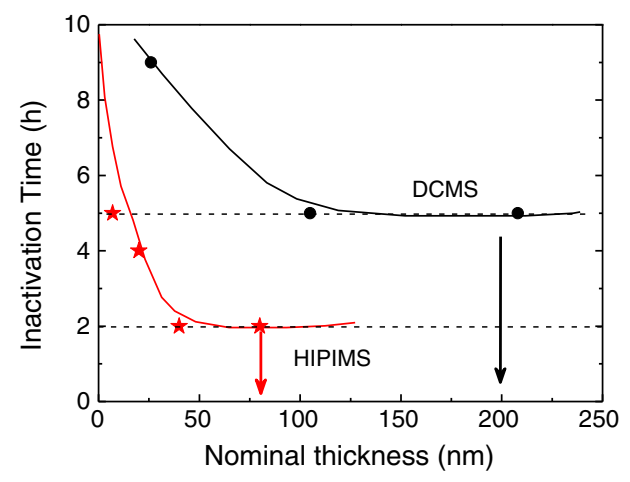

Fig. 5. Inactivation times as a function of the nominal thickness of the Ag-layers deposited by HIPIMS at $5 \mathrm{~A}$ and DCP at $0.3 \mathrm{~A}$.
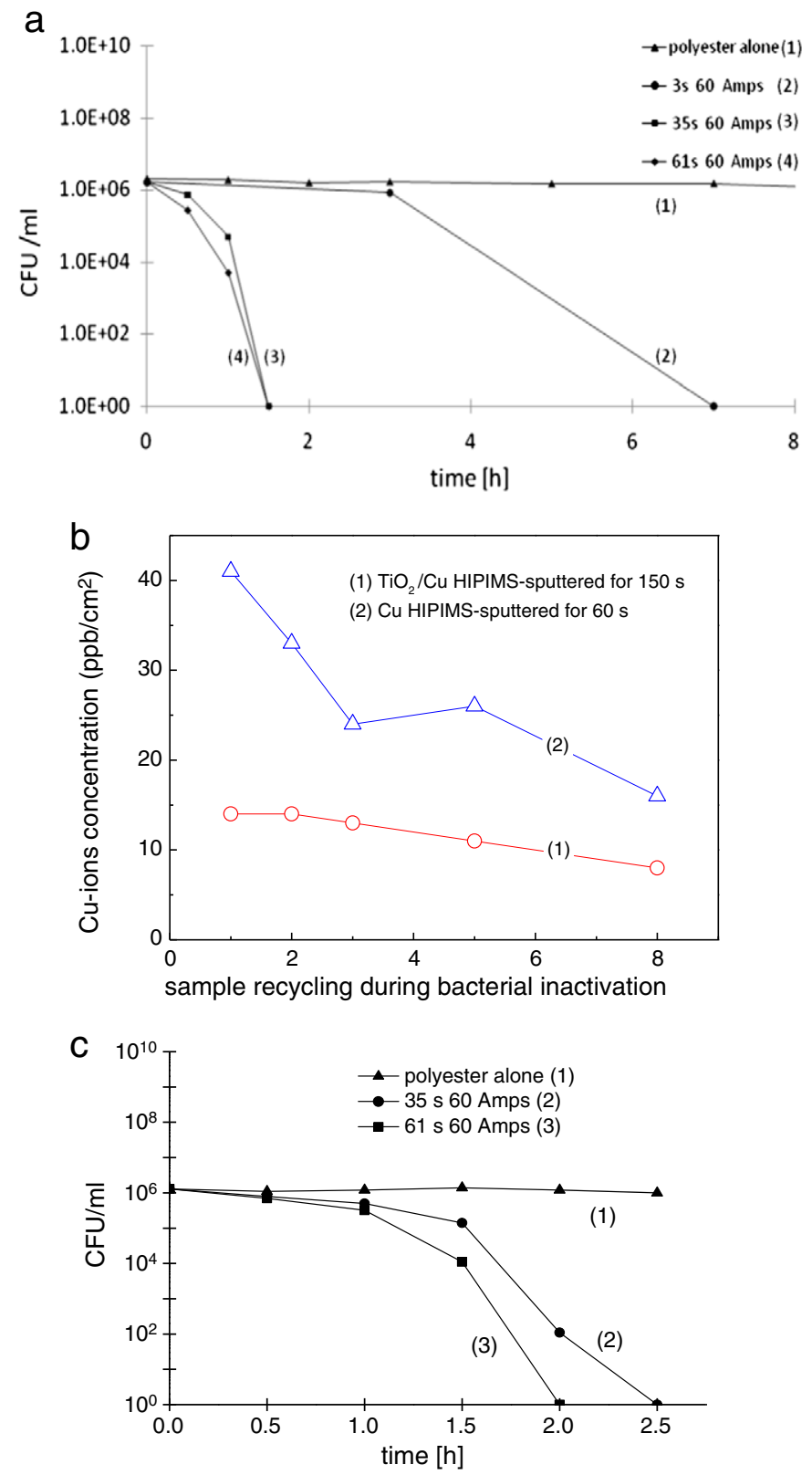

Fig. 6. a. Kinetics of E. coli inactivation in the dark mediated by Cu-polyester HIPIMS sputtered at $60 \mathrm{~A}$. b. Concentration of ions eluted into solution determined by ICP-MS up to the 8th repetitive use of a $\mathrm{TiO}_{2} / \mathrm{Cu}$ inactivating E. coli K-12. c. Kinetics of methicilin resistant Staphylococcus aureus (MRSA) inactivation by Cu-polyester fabrics HIPIMS sputtered at $60 \mathrm{~A}$, in the dark times, the surface \% of C-stabilizes due to the presence of death bacteria up to $90 \mathrm{~min}$. The $\mathrm{Cu} \%$ present is seen to decrease after time zero due to the presence of surface carbon up $90 \mathrm{~min}$.

The XPS-spectrogram of the $\mathrm{Cu}$-samples presented $\mathrm{Cu}\left(2 \mathrm{p}_{3 / 2}\right)$ and $\mathrm{Cu}\left(2 \mathrm{p}_{1 / 2}\right)$ peaks centered at 934.2 and $954.1 \mathrm{eV}$ and this doublet is attributed to the presence of the $\mathrm{Cu}^{2+}$ oxidation state $\left(\mathrm{Cu}^{2+}\right)$ prevalent in the oxidized form of the Cu-sputtered sample exposed to air [35,39]. We suggest based on the evidence of the XPS data that the production of reactive oxygen species (ROS) inside $E$. coli leading to bacterial inactivation involves the redox catalysis $\mathrm{Cu}^{2+} / \mathrm{Cu}^{1+}$ by reactions after contacting the bacteria in the dark as noted below

$\mathrm{Cu}^{+}+\mathrm{O}_{2}^{--} \leftrightarrow \mathrm{Cu}^{\mathrm{o}}+\mathrm{O}_{2}$

$\mathrm{Cu}^{0}+\mathrm{O}_{2} \leftrightarrow \mathrm{Cu}^{+}+\mathrm{O}_{2}^{--}$

The $\mathrm{Cu}^{2+}$ is able to enhance the ROS formation via Fenton like reaction [39]

$\mathrm{Cu}^{2+}+\mathrm{e}-{ }_{\mathrm{cb}} \leftrightarrow \mathrm{Cu}^{+}$

or by a two electron transfer from $\mathrm{Cu}^{2+}$ leading to $\mathrm{Cu}^{\circ}$ atoms

$\mathrm{Cu}^{2+}+2 \mathrm{e}^{-} \leftrightarrow \mathrm{Cu}^{\circ}$

The $\mathrm{Cu}$-atoms then coalesce to $\mathrm{Cu}^{\circ}$ nanoparticles settling in the $\mathrm{Cu}-$ network of the polyester with $\mathrm{E}_{\mathrm{redox}}=-0.34 \mathrm{~V}$ vs. NHE [40].

\subsection{Ag and Cu-ions sputtered by HIPIMS and DCMS determined by mass spectroscopy (QMS)}

Fig. 7 presents the ion-composition when sputtering Ag by HIPIMS in an $\mathrm{Ar}$ atmosphere by QMS. The Ag presents ionization potentials of $7.6 \mathrm{eV}$ for $\mathrm{Ag}^{+}$and $21.5 \mathrm{eV}$ for $\mathrm{Ag}^{2+}$ compared with the buffer gas $\mathrm{Ar}^{+}$of $15.7 \mathrm{eV}$. When increasing current, the amount of $\mathrm{Ar}^{+}$-ions decreases and the $\mathrm{Ag}^{+}$-ions in the gas phase increase. At discharge cur-

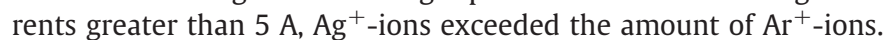
The most interesting result was found for the $10 \mathrm{~A}$ peak current leading to high quantities of $\mathrm{Ag}^{+}$-ions with a small amount of $\mathrm{Ag}^{2+}$-ions. In the current experiments HIPIMS power densities are at least a factor of 4-10 higher compared to DCMS leading to a significant difference in the ionflux composition in Fig. 7. The composition of HIPIMS at the lowest current of $1 \mathrm{~A}$ (current density of $20 \mathrm{~mA} / \mathrm{cm}^{2}$ ) was similar to the case of DCMS sputtering with a current of $300 \mathrm{~mA}$ (current density of $15.3 \mathrm{~mA} / \mathrm{cm}^{2}$ ). In the presence of $\mathrm{O}_{2}$ the $\mathrm{Ag}^{2+}$-ion leads to $\mathrm{AgO}$ [40].

Fig. 8 presents the ion-composition when sputtering $\mathrm{Cu}$ by direct current magnetron sputtering (DCMS) and HIPIMS in Ar-atmosphere from QMS analysis. The ionization potential of $\mathrm{Cu}^{+}$is $7.7 \mathrm{eV}$. By inspection of Fig. 8, the composition of the ions in the DCMS chamber gas phase was: $87 \% \mathrm{Ar}^{+}, 5 \% \mathrm{Ar}^{2+}$ and $8 \% \mathrm{Cu}^{+}$. Low amounts of $\mathrm{Cu}^{+}$-ions were found for the DCMS-sputtered samples. The amount of $\mathrm{Cu}^{+}$-ions increases with HIPIMS at 6 Amps to reach $97 \%$ along $3 \% \mathrm{Ar}^{2+}$. Finally, at $60 \mathrm{Amps}$ the composition of the gas phase is: $17 \% \mathrm{Ar}^{+}, 3 \% \mathrm{Ar}^{2+}$, $75 \% \mathrm{Cu}^{+}$and $5 \% \mathrm{Cu}^{2+}[41,42]$. Because of the different power applied by HIPIMS the ion trajectory in the plasma and subsequent condensation on the substrate surface proceed with a different diffusion and condensation in the case of HIPIMS compared to DCMS. HIPIMS leads to less voids and denser films. In general the cluster size is reduced. But especially for Ag-HIPIMS there is literature showing that the opposite happens. It is expected that the percolation threshold will be reduced. Nevertheless the silver atoms and especially the ions tend to from clusters instead of growing a flat uniform film. Therefore the percolation happens later-at higher film thickness. This might be also one reason for the Ag-activity. Since the film is forming nanocrystalline clusters the effective surface area is increased (fractional surface). This leads to 
Table 3

Surface atomic composition concentration \% of the main elements on the polyester Cu-sputtered by HIPIMS for $60 \mathrm{~s}$ at 60 Amps

\begin{tabular}{|c|c|c|c|c|c|c|c|}
\hline Sample & $\mathrm{C}$ & 0 & $\mathrm{~N}$ & $\mathrm{Cu}$ & $\mathrm{Na}$ & $\mathrm{P}$ & $\mathrm{Cl}$ \\
\hline Polyester blank & 75.30 & 23.13 & & & 1.21 & 0.36 & \\
\hline Polyester $+\mathrm{Cu}$, time zero & 53.76 & 26.50 & & 19.74 & & & \\
\hline Polyester $+\mathrm{Cu}+$ bacteria, time zero & 44.81 & 32.63 & 0.48 & 14.08 & 2.80 & 2.19 & 0.31 \\
\hline Polyester $+\mathrm{Cu}+$ bacteria (30 min) & 68.89 & 22.04 & 1.14 & 1.76 & 3.70 & 0.35 & \\
\hline Polyester $+\mathrm{Cu}+$ bacteria (60 min) & 60.29 & 25.90 & 0.35 & 4.59 & 3.15 & 0.93 & \\
\hline Polyester $+\mathrm{Cu}+$ bacteria (90 min) & 61.13 & 23.84 & 0.20 & 4.35 & 3.56 & 6.11 & \\
\hline
\end{tabular}

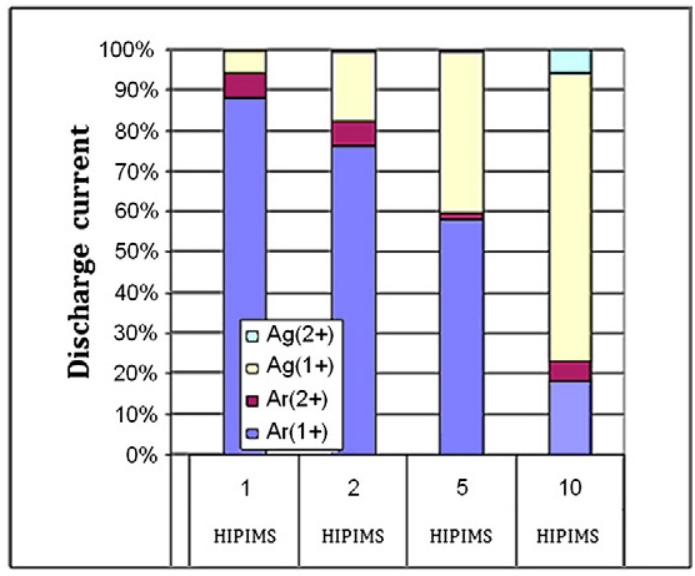

Fig. 7. Plasma ion-composition analysis of HIPIMS in argon, derived from mass spectroscopy analysis. HIPIMS is applied at different currents as indicated in the figure.

higher reactivity and possibly to higher cell death rate. Smaller metal lattice constants have been reported by XRD for the HIPIMS layers compared to DCMS layers usually deposited using lower energies [25-33].

The HIPIMS runs show that with increasing current, the $\mathrm{Ar}^{2+}$ and $\mathrm{Cu}^{2+}$ in the gas phase increase. During the magnetron sputtering chamber, the ionization $\mathrm{Ar} \leftrightarrow \mathrm{Ar}^{+}+\mathrm{e}^{-}$leads in a subsequent step to the collision of the electron with $\mathrm{e}^{-}+\mathrm{Cu}^{\circ} \leftrightarrow \mathrm{Cu}^{+}+2 \mathrm{e}^{-}$. The high-speed electron during the physical collision with the Cu kicks off a second electron leading to the $\mathrm{Cu}^{+}$-ion. In the case of HIPIMS, the metal-ions with a higher e-density interact more readily with biased polyester in the magnetron chamber.

\section{Conclusions}

This study presents the surface functionalization of polyester by very thin sputtered $\mathrm{Ag}$ and Cu-layers inducing accelerate E. coli inactivation in the dark (minute range). The thin $\mathrm{Ag}$ and $\mathrm{Cu}$ films were uniform and presented adhesive properties and their stability led to repetitive loss of bacteria viability. A considerable saving in metal and deposition time (energy) was found for HIPIMS sputtered surfaces compared to conventional DCMS-sputtered surfaces. Increasing demand for $\mathrm{Ag} / \mathrm{Cu}$

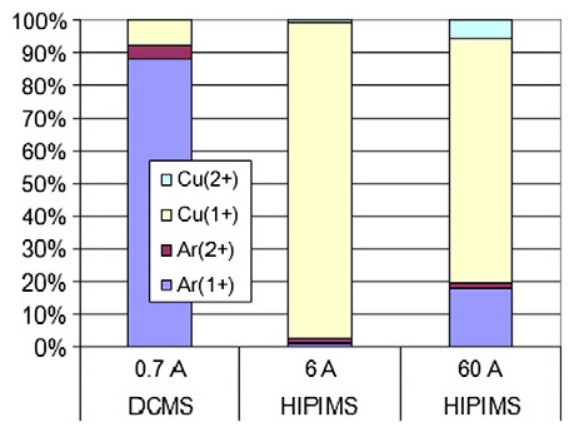

Fig. 8. Ar-ion composition and Cu-ion composition determined by mass spectrometry in the gas phase for a DCMS and a HIPIMS sputtering chamber. For other details see text. is decreasing rapidly the known world reserves. This is important since both metals are strategically important metal. These films preclude biofilm formation spreading infectious bacteria of all sorts in hospitals, schools, and public places. The films developed in this study present a practical application potential for the preparation of a variety of disinfecting surfaces.

\section{Acknowledgments}

We thank the EPFL and the Swiss National Science Foundation (SNF) for the financial support under the project: Preparation, testing and characterization of innovative intravascular catheters inactivating bacteria by contact (oligodynamic effect). We also thank the COST actions MP0804 and MP1106 for interactive discussions during the course of this study.

\section{References}

[1] A. Kramer, I. Schwebke, G. Kampf, BMC Infect. Dis. 6 (2006) 130-138.

[2] K. Taylor, R. Roberts, J. Roberts, The challenge of hospital acquired infections (HAI), Nat. Audit Office, 2002.

[3] K. Page, M. Wilson, I.P. Parkin, J. Mater. Chem. 12 (2009) 3819-3831.

[4] T. Yuranova, A. Rincon, A. Bozzi, S. Parra, C. Pulgarin, P. Albers, J. Kiwi, J. Photochem. Photobiol. A 161 (2003) 27-34.

[5] T. Yuranova, A. Rincon, C. Pulgarin, D. Laub, N. Xanthopoulos, H.-J. Mathieu, J. Kiwi, J. Photochem. Photobiol. A 181 (2006) 363-369.

[6] G. Borkow, J. Gabbay, J. FASEB (2008) 1728-1730.

[7] G. Borkow, J. Gabbay, Med. Hypotheses 70 (2008) 990-994.

[8] L. Zhang, R. Dillert, D. Bahnemann, M. Vormoor, Energy Environ. Sci. 5 (2012) 7491-7507.

[9] H. Foster, I. Ditta, S. Varghese, A. Steele, Appl. Microbiol. Biotechnol. 90 (2011) 1847-1868.

[10] H.M. Yates, L.A. Brook, I.B. Ditta, P. Evans, H.A. Foster, D.W. Sheel, A. Steele, J. Photochem. Photobiol. A 197 (2008) 197-2005.

[11] J. Musil, M. Louda, R. Cesrtvy, P. Baroch, I.B. Ditta, A. Steele, H.A. Foster, Nanoscale Res. Lett. 4 (2009) 313-320.

[12] L.A. Brook, P. Evans, H.A. Foster, M.E. Pemble, A. Steele, D.W. Sheel, H.M. Yates, J. Photochem Photobiol. A 187 (2007) 53-63.

[13] I. Sondi, S. Sondi, J. Colloid Interf. Sci. 275 (2004) 177-182.

[14] P.V. Ashrani, G.L. Mun, M.P. Hande, S. Valyaveettil, ACS Nano 3 (2009) 279-290.

[15] J. Liu, D. Sonshine, S. Shervani, R. Hurt, ACS Nano 4 (2010) 6903-6913.

[16] S. Dancer, J. Hosp. Infect. 73 (2009) 378-385.

[17] F. Heidenau, W. Mittelmeier, R. Detsch, M. Haenle, F. Stenzel, G. Ziegler, H.A. Gollwitzer, J. Mater. Sci. Med J. Mater. Sci. Med. 16 (2005) 883-889.

[18] T. Ehirai, H. Tsuchiya, T. Shimizu, K. Ohtani, Y. Zen, K. Tomita, J. Biomed. Mater. Res. B Appl. Biomater. 91 (2009) 373-380.

[19] M. Haenle, A. Fritsche, C. Zietz, R. Bader, F. Heidenau, W. Mittelmeier, H. Gollwitzer, Mater. Sci. Mater. Med. 22 (2011) 381-387.

[20] K. Sunada, S. Watanabe, K. Hashimoto, Environ. Sci. Technol. 40 (2003) 4785-4789.

[21] J. Kiwi, C. Pulgarin, Catal. Today 151 (2001) 2-7.

[22] A. Torres, C. Ruales, C. Pulgarin, A. Aimable, P. Bowen, J. Kiwi, Appl. Mater. Interfaces 1 (2010) 2547-2552 (65 m2/g).

[23] Thüringer Surface and Biomaterials Kolloquium, Zeulenroda, Germany, 13-15 September 2011.

[24] 22nd Annual BioInterface Conference 2012, University College Dublin, Ireland, October 23-25 2012.

[25] J. Lin, J. Moore, W. Sproul, B. Mishra, Z. Wu, L. Wang, Surf. Coat. Technol. 204 (2010) 2230-2239.

[26] K. Sarakinos, J. Alami, D. Konstantinidis, Surf. Coat. Technol. 204 (2010) 1661-1684.

[27] A. Petrov, J. Myers, E. Greene, J.R. Abelson, J. Vac. Sci. Technol. A 12 (1994) 2846-2851.

[28] J. Alami, P. Persson, J. Gudmunsoon, J. Bohlmark, J. Helmersson, J. Vac. Technol. A 23 (2005) 278-280.

[29] V. Kousznetsov, K. Macak, J. Schneider, U. Helmersson, I. Petrov, Surf. Coat. Technol. 12 (1999) 290-295.

[30] A. Ehiasarian, Pure Appl. Chem. 82 (2010) 1247-1258.

[31] A. Ehiasarian, A. Vetushka, A. Hecimovic, 1 S. Konstantinidis, J. Appl. Phys. 104 (2008) 083305. 
[32] A. Ehiasarian, Y. Gonzalvo, T. Whitmore, Plasma Process. Polym. 4 (2007) 5309-5313.

[33] Laura Rio, Ewelina Kusiak, John Kiwi, César Pulgarin, Andrej Trampuz, Alain Bizzini, Appl. Environ. Microbiol. 78 (2012) 8176-8182.

[34] D. Briggs, M. Shea, Practical Surface Analysis, 2nd edition, Auger and X- rays, vol. 1, John Wiley \& Sons, Chichester, New York, Toronto, Singapore, 1988.

[35] C. Wagner, M. Riggs, E. Davis, G. Mullenberg, E. G (Eds.), Handbook of X-Ray Photo-electron Spectroscopy, Perkin-Elmer Corp. Physical Electronics Division, Minnesota, 1979.

[36] A.D. Shirley, Phys. Rev. B5 (1972) 4709-4716.

[37] J.W. Mathews, Epitaxial growth, Part B, Ch 4: Nucleation and Thin Films, Academic Press, New York, 1975. 382.
[38] M. Heinlaan, I. Blinova, H.-C. Dubourguier, A. Kahru, Chemosphere 71 (2008) 1308-1316.

[39] G. Biederman, G. Sillen, Acta Chem. Scand. Part 3014 (1969) 14-0717.

[40] O. Baghriche, A.P. Ehiasarian, E. Kusiak-Nejman, A.W. Morawski, C. Pulgarin, R. Sanjines, J. Kiwi, J. Photochem. Photobiol. A 227 (2012) 11-17.

[41] O. Baghriche, R. Sanjines, C. Pulgarin, S. Rtimi, J. Kiwi, J. Photochem. Photobiol. A 251 (2013) 50-56.

[42] E. Kusiak-Nejman, A.W. Morawski, A.P. Ehiasarian, O. Baghriche, C. Pulgarin, E. Mielczarski, J. Mielczarski, A. Kulik, J. Kiwi, J. Phys. Chem. C 115 (2011) 21113-21119. 